\title{
5. Building institutional capacity for sustainability science
}

Promoters of sustainability science within the research and policy-making community face the critical challenge of establishing this new field of research as a recognized scientific practice. In spite of the growth of the sustainability science community, the challenge remains a particularly difficult one as sustainability science leads to two main transformations of conventional science practice: first, the adoption of the methodological tools and epistemology of interdisciplinary analysis of socio-ecological systems and, second, the adoption of a participatory transdisciplinary research practice to overcome the dichotomy between science and society in governing the transition towards sustainability.

\subsection{OVERCOMING DISCIPLINARY INERTIA IN THE DEVELOPMENT OF SUSTAINABILITY SCIENCE}

As sustainability problems are complex, scholars are confronted with the crucial task of integrating knowledge and information from various academic disciplines, including natural sciences, engineering, social sciences and humanities. However, the current trend is that the academic landscape consists of separate clusters of individual disciplines (Kajikawa et al., 2007). Few studies have analysed the actual practice of interdisciplinarity in sustainability science. One way to analyse such practice is to look at bibliometric data and to analyse the existing interdisciplinary practice based on a simple metric of the "tripartite" model of sustainability, which envisions sustainability as the combination of equitable economic growth, social well-being, and a thriving natural resource basis (Schoolman et al., 2012). As we have shown in this book, this tripartite model needs to be further refined, in particular in relation to the way the role of economic growth is envisioned in the model. Nevertheless, for the purpose of assessing the current situation of published interdisciplinary research on sustainability, this model provides a good starting point.

On 30 April 2012, Ethan Schoolman and his team published a bibliometric analysis of the articles containing the word "sustainability" in 


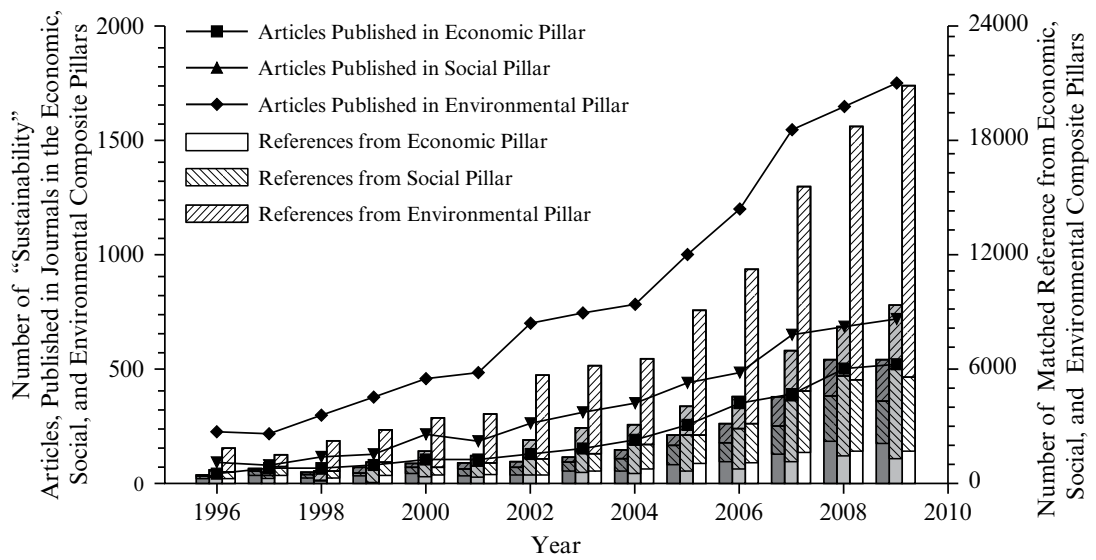

Notes: Number of articles (lines with filled symbols, left axis) and number of corresponding references (stacked bars, right axis) from composite sustainability pillars: economic (left bar, squares); social (centre bar, triangles); environmental (right bar, diamonds). The classification of references sources is indicated by the bar hatchings.

Source: Schoolman et al. (2012).

Figure 5.1 Bibliometric analysis of articles on sustainability (I)

either the title or keywords, in the approximately 16500 peer-reviewed journals of the Scopus database that were published between 1996 and 2009 (Schoolman et al., 2012). The goal of their analysis was to answer three questions: (1) is sustainability research truly more interdisciplinary than research generally? (2) to what extent does research grounded in one pillar draw on research from the other two? and (3) if certain disciplines or pillars are more interdisciplinary than others, what explains this variation? The results are shown in Figure 5.1.

Figure 5.2 compares the references to other pillars in each of the disciplines. The result clearly shows that articles with the key word "sustainability" (the circles) are more interdisciplinary than scientific research generally (the filled symbols). The two figures combined show that most "sustainability" publications are publications in the environmental pillar, but that sustainability papers in environmental journals tend be far more mono-disciplinary (the crossed circles at the top of Figure 5.2) than sustainability papers in the social and economic journals (the other circles in Figure 5.2).

These results indicate that sustainability science, while more interdisciplinary than other scientific fields, falls short of the expectations inherent in the tripartite model. The pillar with the fewest published articles on 


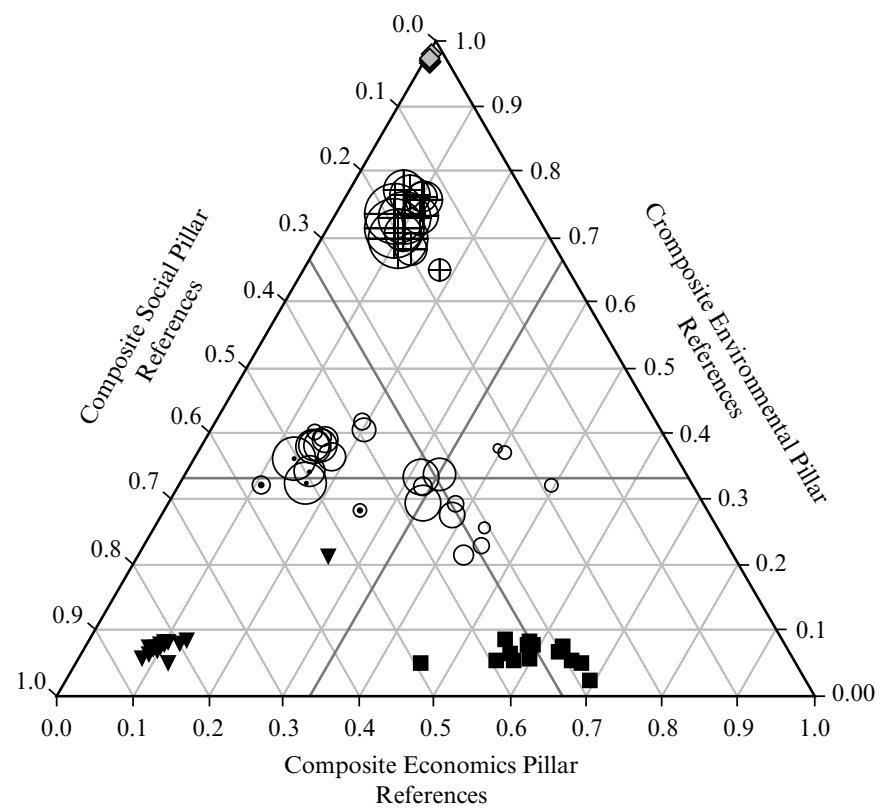

Notes: References to research in other pillars in sustainability research. Annual averages of "sustainability" (hollow circles) and "baseline" (filled symbols) articles from each pillar: economics (empty circles and filled squares); social (dotted circles and filled triangles); environmental (crossed circles and filled diamonds).

Source: Schoolman et al. (2012).

Figure 5.2 Bibliometric analysis of articles on sustainability (II)

sustainability - economics - is also the most integrated, while the pillar with the most articles - environmental sciences - draws the least from other disciplines. Closer analysis of these results by Schoolman and his team shows that interdisciplinarity comes at a cost: sustainability research in economics and the social sciences is centred around a relatively small number of interdisciplinary journals, which, although growing, have become comparatively less valued over time, when compared to the growth of mono-disciplinary journals (Schoolman et al., 2012, p. 77). Nearly 70 per cent of sustainability articles in the economics pillar and 68 per cent of those in the social science pillar are from journals cross-listed in the Scopus journal database with at least one other pillar. But as sustainability publishing in economics and social sciences is centred on a small number of cross-listed journals (and the majority of journals in the Scopus database are not cross-listed, i.e. are mono-disciplinary), then it seems possible that 
interest in sustainability science may have difficulty growing beyond these journals and reaching a wider audience.

As indicated by Schoolman et al. (2012, p. 78), the results of this study are consistent with the idea that disciplinary inertia and institutional obstacles have had an impact on the structure of sustainability science. Where sustainability research has the widest audience - in the environmental sciences - incentives to establish connections across "pillars" of knowledge, such as the social and economic analyses, are probably reduced, and we find that fewer such connections are made. Where the number of sustainability publications is still relatively small - in economics and the social sciences - researchers have strong reasons to establish connections with scholars across academia. In addition, the relatively insular nature of interdisciplinary work on sustainability in the economic and social pillars makes it difficult to reach a wider audience.

The findings of this review suggest that, if sustainability science is to live up to its interdisciplinary and transdisciplinary research requirements, researchers must be provided with greater incentives to draw from other fields than their own. To address the complex sustainability issues therefore requires practical strategies for integrating the key features of interdisciplinarity and transdisciplinarity in the existing research environment and to overcome the institutional and organizational barriers to reaching that goal.

\subsection{MAJOR INSTITUTIONAL BARRIERS FOR THE DEVELOPMENT OF SUSTAINABILITY SCIENCE}

Scholars have identified a set of major institutional hurdles to be overcome in establishing sustainability science as a major recognized scientific research practice on the same footing as other well-recognized research programmes focused on socially relevant operational issues (such as engineering and medicine - so-called "relevant" research, see European Commission, 2009, p. 12). These include the further development of interdisciplinary methodologies encompassing the social and environmental sciences, the transformation of institutional structures (such as incentives for conducting research and career reward systems) (van der Leeuw et al., 2012), the initiation of collaboration with stakeholders outside of academia (Yarime, 2011), as well as the development of a coherent set of sustainability competences and effective pedagogical approaches (Wiek et al., 2011).

Underlying several of the institutional, organizational and pedagogical barriers is the belief by scientists, science policy makers and funders that taking a programme-oriented, relevant-science approach is going beyond 
the remit of science (Jaeger, 2009). Indeed, sustainability scientists clearly not only analyse problems and discuss possible solutions, but also support the implementation of measures to deal with the problems at hand in collaboration with key stakeholders and assume the role of an active participant from the point of view of a normative interest in strong sustainability issues (Jaeger, 2011, p. 196). However, academic and other basic research institutions rarely give credit for the kind of transdisciplinary research effort envisioned by sustainability science.

A second barrier is the existing research evaluation procedure, which generally does not support the type of open, iterative and adaptive learning processes with stakeholders that characterize sustainability science (Weaver and Jansen, 2004). As a practical and normative-oriented science, sustainability science cannot determine a specific objective ex ante, because the problem to be dealt with has to be agreed first with the other stakeholders, and the normative goals and values need to be clarified during the research process itself with these research partners (see the discussion of the ecological footprint indicator in Chapter 2). In other terms, sustainability science is "goal-searching" and not "goal-driven" (Weaver and Rotmans, 2006). Furthermore, external evaluation is often ill-equipped to deal with the adaptive management explicitly built into the project, to allow adaptive learning both from initial solutions and failures (Jaeger, 2011, p. 196; Ostrom et al., 2007).

In addition, as argued by Susanne Lohmann (2007), procedures for reviewing manuscripts, grant applications and applications for academic positions and promotions strongly favour specialization. All these forms of evaluation rely on mono-disciplinary peer review. As Lohmann notes, peer review generally means that the work of a specialist is reviewed by other specialists in the same method, with the same area of expertise and/or with the same or similar substantive concerns. Scholars who engage in multiple methods or disciplines, in a transdisciplinary research context, will probably be evaluated by disciplinary specialists rather than other practitioners of multi-method or transdisciplinary research. In this process, Lohmann argues, the reviewers are not likely to fully understand all the methods, the rationale for mixing methods, or the challenges involved in multi-method research. Indeed, specialists tend to discount the results of unfamiliar methods, references to works in other fields, publications in journals outside their own discipline, and interdisciplinary publications.

A third major barrier is related to the lack of educational approaches that are problem driven and that promote experiential learning in multistakeholder contexts. The acquisition of competences that are key to sustainability science (Wiek et al., 2011), such as "strategic competences" (the ability to collectively design and implement transformative governance 
strategies towards sustainability) and "normative competences" (the ability to collectively map and negotiate sustainability values, principles and goals) are clearly not part of the requirements to be fulfilled in the usual science curriculum, while other core competences, such as complexsystems thinking and long-term future-oriented scenario building have only been integrated to a limited extent in academic training. Considering the core characteristics of sustainability science, it seems reasonable that students should acquire in-depth expertise in one or two of the key competences of sustainability science and a solid grounding in the others.

As shown by Amy Poteete and her co-workers (Poteete et al. 2010, p. 19), the requirements for training for sustainability science contrast with the existing supply of intensive methodological training curricula and programmes at graduate and post-graduate level. Training in quantitative methods has been a standard component of graduate programmes in economics, political science and sociology throughout the post-war period. Likewise, opportunities to supplement in-house courses with intensive training in more specialized quantitative methods have been available for decades. By comparison, options for training in interdisciplinary quantitative and qualitative methods were rare until recently. Even if the opportunities for such training are growing, students and researchers interested in multi-method interdisciplinary research find it still difficult to gain adequate training in non-quantitative methods (Siegel et al., 2007).

A final hurdle for the field of sustainability science is the lack of appropriate mechanisms for organizing the participation by legitimate communities and stakeholder groups (van der Leeuw et al., 2012, p. 118). Often, reaching and involving relevant communities is complicated by language and cultural differences, insufficient expertise, lack of empathy as well as lack of time. Even when the correct people are gathered together in the same room, negotiating personalities, languages and cultures can be overwhelming. Power disparities among stakeholders and trust in the process can limit participation even when attendance is achieved (van der Leeuw et al., 2012). These tensions between scientific and extra-scientific expertise may stem from the reality that academics have little experience of conducting participatory research. Moreover, these shortfalls are more likely to occur in a higher educational system that fails to train students in experiential learning in multi-stakeholder contexts. In today's system institutional rewards for researchers are predicated on high impact journals where action-oriented research is not well represented, and where academic research projects rarely fit the long-term relationship and capacity building required for meaningful participatory engagement and transformative change.

Most of the barriers to a major, consolidated effort in sustainability 
science will not be removed without far-reaching institutional change (Jaeger, 2011, p. 197): first, changes in the educational system to strengthen the core competences of sustainability science are necessary; second, collaboration and networking with stakeholders in society around common sustainability objectives need to be expanded and deepened; third, the existing institutions that support science and technology in the current governance structure for knowledge require major adjustments in order to improve the link between science, policy and society. The following sections briefly review each of these three tasks of institutional capacity building for sustainability science.

\subsubsection{Incorporating Sustainability into Higher Education Institutions}

In attempting to further establish sustainability science in academia and basic research institutions, scholars and policy makers have to manage the complex process of the institutionalization of a scientific field. This process encompasses the founding of educational and research programmes, the establishment of academic societies and associations, as well as scientific journals and textbooks (Ben-David, 1971). Of these many challenges, probably the greatest of all concerns the transformation of the core missions of the modern research university. The integration of research into the core activities of the modern university during the nineteenth century signified the first major transformation of higher education institutions. During the twentieth century, the capitalization of scientific knowledge in the service of the economy in the so-called "entrepreneurial university" has led to a second major transformation. At present, the new modes of organization of research called for by the sustainability transition could lead to a third major transformation, called by some the "third academic revolution". The focus of this third transformation will be on the sustainable development of the local and regional communities associated with the major research universities and on the promotion of larger socio-technological transitions towards strong sustainability (Yarime et al., 2012, p. 109).

Both the current incentive and reward system of the research university and the existing mode of university/industry collaboration in the service of the needs of industry remain important and well-established social benefits of modern higher education institutions. However, they are clearly insufficient for implementing the type of multi-stakeholder collaborations required for solving complicated and interconnected sustainability issues.

The concept of sustainability was first introduced in higher education systems at an international level by the UNESCO-UNEP International Environmental Education Programme in 1975, jointly administered by the United Nations Educational, Scientific and Cultural Organization 
(UNESCO) and the United Nations Environment Programme (UNEP) (UNESCO, 1984). Since then, a number of national and international declarations relating to the integration of sustainability issues in higher education institutions have been developed (Wright, 2004; Yarime et al., 2012). The Talloires Declaration of 1990 (University Leaders for a Sustainable Future (ULSF), 2011) was the first official declaration made by university presidents, chancellors and rectors of a commitment to sustainability in higher education. This declaration proposed an action plan for incorporating sustainability in teaching, research, operations and outreach at colleges and universities (ULSF, 1990). It was soon followed by the Swansea Declaration adopted at the conclusion of the Association of Commonwealth Universities' Fifteenth Quinquennial Conference in 1993.

At the European level, an early initiative was the Co-operation Program in Europe for Research on Nature and Industry through Coordinated University Studies (COPERNICUS), which was established by the Conference of Rectors of Europe (CRE) to promote a better understanding of the interaction between humans and the environment and to collaborate on common environmental issues. In this context, the Conference of Rectors created the CRE COPERNICUS Charter for Sustainable Development in 1994 and co-organized the COPERNICUS conference held for the World Summit on Sustainable Development Rio+10, which led to the Lüneburg Declaration on Higher Education for Sustainable Development in 2001.

Finally, on the global scale, another important declaration in the early period of the establishment of sustainability science was the Ubuntu Declaration on Education and Science and Technology for Sustainable Development in 2002, with the signatories of major academic institutions such as the United Nations University (UNU), the International Association of Universities, the Third World Academy of Science, the African Academy of Sciences and the Science Council of Asia, as well as the International Council for Science, amongst others.

A variety of frontier education programmes have been implemented for integrating sustainability at higher education institutions since these major declarations were developed in the 1990s. A well-established programme, focusing on transdisciplinary education in complex sustainability issues, is the Graduate Program in Sustainability Science (GPSS) of the Graduate School of Frontier Sciences at the University of Tokyo, introduced in 2007 (Onuki and Mino, 2009). The core of this programme consists of the provision of integrated and holistic approaches, along with case study analysis of particular situations to learn the necessary skills for applying such approaches to major sustainability issues. Through a variety of case studies students learn skills such as systems thinking, facilitation and 
negotiation necessary for consensus building, and sound understanding and appreciation of cultural diversity. Throughout these case studies, students are urged to revise and reformulate the problems at hand and acquire a comprehensive understanding distinct from the implicit assumptions made in formulating the original problem.

One of the major features of the programme is its collaboration with policy makers and stakeholders outside academia established at the University of Tokyo. For example, through the involvement of the graduate school in the project on a bright low-carbon society (for the low-carbon development of Kashiwa City) students from various graduate programmes actively participate in the diverse social experiments of each research group (Onuki and Mino, 2009). By doing so, they learn transdisciplinary approaches to interwoven problems which require technical solutions, collective action and open-ended ethical goal-setting. As various types of stakeholders in society are involved in these social experiments, students can also learn how to communicate effectively with people and organizations that do not necessarily share or understand academic terminologies and curiosities. This educational role is then extended to the community and to the stakeholders involved, all of whom may monitor and appropriate the results via annual public conferences, grey literature (reports, online working papers, etc.) and academic journals.

Extra-academic collaborative and participative sustainability research has been established at various higher education institutions throughout the world. Although this model of the reform of higher education institutions is still in its initial stages, these programmes nevertheless show promising strategies for integrating sustainability issues into higher education through experiential learning, based on in-depth case study methodologies and collaboration and networking with external stakeholders. In addition, opportunities for intensive training in qualitative methods and in multimethod research have expanded over the past decade (see Poteete et al., 2010, p. 19). For example, the consortium on qualitative research methods holds an annual intensive seminar on qualitative and multi-method research. The US National Science Foundation has supported methodological training programmes for the social sciences, including month-long courses such as the Empirical Implications of Theoretical Models (EITM) programme, which offer training in how to combine multiple quantitative methods within a single research programme (Granato et al., 2010a; 2010b). Opportunities to develop more specialized qualitative research skills include the summer school in methods and techniques offered by the European Consortium for Political Research and, in the United States, the Inter-University Consortium for Political and Social Research.

Overall, progress on campuses has, however, been rather slow (Velazquez 
et al., 2005). This slow pace of higher educations' movement towards sustainability has been particularly influenced by the conventional university appraisal systems that do not seriously consider sustainability perspectives in their evaluation methodologies (Yarime et al., 2012, p. 104). Currently, higher education systems are under considerable pressure to perform on citation indexes and technology transfer statistics, which give only a partial picture of the universities' social role, especially if they invest in extraacademic collaborative and participative sustainability research. If modified appropriately, assessment and appraisal systems could be a significant force for promoting the integration of sustainability research in higher education institutions (Fadeeva and Mochizuki, 2010).

To achieve a far-reaching impact, research administrators and science policy officials should design and implement sustainability assessments of higher education institutions in an integrated manner (Yarime et al., 2012, p. 104). Sustainability assessment systems of educational institutions usually evaluate issues such as: the usage of energy, water and other materials; sustainability education as a core function along with the incorporation of sustainability issues in teaching, research and service; and cross-institutional actions (Shriberg, 2002). Most existing assessment systems, however, evaluate the aspects of education, research and outreach rather separately. To encourage higher education institutions to move more effectively and consistently towards sustainability, university appraisal systems should provide a holistic assessment that encompasses the establishment of academic programmes based on experiential learning, institutionalization of sustainability research communities and networks, and collaboration with external stakeholders involved in sustainability projects (Yarime et al., 2012, p. 104).

\subsubsection{Strengthening the Sustainability Science Community}

As witnessed by the endorsement and signature of the major international declarations, the research and science policy community shows a growing interest in embracing sustainability issues in research and education. The community actively pursuing sustainability science is, however, highly fragmented (Jaeger, 2011, p. 192). Except for some major initiatives discussed below, the communities and networks of sustainability scientists that currently exist are often oriented towards specific topics, such as climate change, development, water management or biodiversity. Prominent examples of these "topical" communities on the global scale are the Earth System Science Partnerships for the integrated study of the earth system discussed in section 3.1.3 above; the Resilience Alliance, which comprises scientists and practitioners who collaborate to explore 
the dynamics of socio-ecological systems (www.resalliance.org) and the Integrated Assessment Society (http://www.tias.uni-osnabrueck.de/tias. php) for the development and use of integrated assessment. However, in spite of the importance of these initiatives and their often path-breaking contributions to sustainability science, they are few in number, without any connection between the participating scientific communities (apart from some individuals).

Several initiatives have been launched to overcome this state of relative fragmentation. Amongst the most important are global networks that gather major university research institutions and a set of non-university research partners (Yarime et al., 2012, p. 108). Historically important networks are the Alliance for Global Sustainability, created in 1997 by four technical universities (the University of Tokyo, MIT, the Swiss Federal Institute of Technology and Chalmers University of Technology) to launch jointly-sponsored sustainability research projects (see Box 5.3 below), the network of Japanese universities initiated by the University of Tokyo in 2005 (the Integrated Research System for Sustainability Science), which launched the journal Sustainability Science with the United Nations University, and the International Network for Sustainability Science in 2009, which organizes the International Conference on Sustainability Science, already in its third meeting in February 2012.

In Europe, the European Sustainability Science Group (ESSG) is a first step in broader community building. As Jill Jaeger has pointed out, the individuals and institutions that form the ESSG are a "good starting point", but the group is at present too small to fully represent sustainability science (Jaeger, 2011, p. 192). In parallel, major national-level research programmes and research networks have been set up that have attracted EU-wide attention such as the Knowledge network on System Innovations (KSI) in the Netherlands or the Network for Transdisciplinary Research at the Swiss Academy of Arts and Sciences. More recently, the transitions research community in Europe has set up a new network, the Sustainability Transitions Research Network (STRN), aimed at supporting the emerging community of researchers by the organization of major conferences, postgraduate courses and programmes and publications. The rationale of this new network, as stated by the initiators, is clearly to overcome the current fragmentation:

In Europe, many fields of research, such as innovation and governance research already have well-established networks. What is currently missing however is a network program that brings together researchers with a common interest in sustainability transitions, but from a variety of different research fields: industrial transformation, innovation and socio-technological transitions; integrated assessment; sustainability assessment; governance of sustainable development; 
policy appraisal; researchers working on reflexive governance; the resilience community; the ecological economics community; groups of energy, environment and sustainability modellers; and a core sustainability transitions community (www.transitions network.org/about).

Incentive structures and institutional frameworks, such as the postgraduate programmes and the international conferences set up by integrative research networks, and the development of long-term career paths based on the competences acquired in these cross-cutting networks, are particularly important for the further institutionalization of the field of sustainability science. By developing extensive mobility and promoting transformational research in collaboration with stakeholders, sustainability science will be able to create promising opportunities for young people not only in academia but also in industry, business and the public sector. Therefore, these emerging institutional arrangements will potentially have significant implications for cementing sustainability science more deeply in society over the long term (Yarime et al., 2012, p. 108).

A crucial step in the development of long-term career paths in sustainability science is the promotion of research opportunities at post-graduate level. Indeed, as stressed by Poteete et al. (2010, p. 260), ideally interdisciplinary scholars should have a solid command of their own method and discipline, but also have sufficient familiarity with other methods and disciplines to engage with them. One strategy for dealing with this trade-off, which has long been used in the biological and physical sciences, is the use of post-doctoral appointments that enable scholars with a $\mathrm{PhD}$ to practise the research skills they have acquired and learn new skills while participating in an interdisciplinary project. If funding for interdisciplinary research centres and networks were to grow, we could see an expansion of such post-doctoral opportunities across the ecological and social sciences and the humanities.

\subsubsection{Developing Long-term Transdisciplinary Research in Sustainability Science}

The involvement of major universities and research institutions in groundbreaking educational programmes and institutional networks clearly contributed to the growing recognition of sustainability science. Several funding agencies (such as the US National Science Foundation and the DG Research of the European Commission, responsible for the Framework Programmes on the Environment) also invested heavily in interdisciplinary and collaborative training and research related to the study of socialecological systems. These activities have led to a large body of literature on transdisciplinary, community-based, interactive and participatory research 
approaches. Yet, to further implement the transformational agenda of sustainability science, cross-sector and multi-stakeholder collaborations in sustainability research need to be promoted on a much broader scale. In particular, researchers and policy makers need to ask what type of joint initiatives and networking with stakeholders will contribute to accelerating local, regional or global transition processes towards sustainability, and what kind of incentives and policies are required to further promote this type of multi-stakeholder-driven collaboration for sustainability in higher education institutions.

In The Third Industrial Revolution, Jeremy Rifkin gives an example of such a major transdisciplinary programme which has led the city of Rome to adopt an innovative sustainability plan for the city's energy policy (Rifkin, 2011, pp. 82-5). The programme, coordinated by the school of architecture of Sapienza University, engaged in multi-stakeholder research to explore an ambitious action plan for revitalizing housing in the city centre along with job creation by attracting high-tech companies in the field of renewable energies and sustainable housing, the building of partnerships with these companies for local energy production based on renewable energies, smart electrical grids for connecting the privately produced energy, and finally a plan for reconnecting the city to local food production systems in the abandoned fields around the suburban areas to decrease the ecological footprint of the city's food consumption needs. This plan received wide support and has been adopted as the official strategic plan by the city of Rome.

A similar initiative was taken in Tokyo, through a collaboration between the local authorities in the district of Kashiwa City and the University of Tokyo (Yarime et al., 2012). This initiative, called the "Urban Reformation Program for the Realisation of a Bright Low Carbon Society" (see above, section 5.2.1), received five years' funding from the national government. The overall aim of the project is to design the blueprint for a low-carbon, elderly-citizen-friendly community in the local vicinity of Kashiwa and to demonstrate its feasibility via a comprehensive series of social experiments. Both basic and applied research is being conducted by six groups: energy (development of solar heating and air-conditioning); senior mobility (trial of super-compact electric vehicles); clinical plant science (senior-citizen education project to alleviate crop diseases); agriculture and landscape planning (promotion of local agriculture and bio-mass production); city planning (unification of project and housing and services for the elderly); and lastly information systems (unification and information management). The partners for this project include the University of Tokyo, local government authorities, a think tank, local enterprises, NGOs and citizen groups. Although still in its initial stages, the project shows how transdisciplinary 
research programmes can be set up to support multi-stakeholder intervention in society and to demonstrate the impact of particular policies or technologies for sustainability.

Urban planning initiatives seem especially suited for sustainability research. However, the emerging sustainability science programmes have not been limited to complex urban transition processes, nor to developing research collaboration with stakeholders looking for basic scientific input for sustainability projects at the planning stage. Transdisciplinary research has been set up for issues as diverse as the development of solar energy systems in rural areas of Argentina (Wiek et al., 2012), community-driven implementation of payment for ecosystem services schemes (Weaver, 2011), and interdisciplinary assessment of synthetic biology contributions to sustainability (Pauwels, 2011), to name just a few. Support for these initiatives by regional and national governments and stakeholders shows that higher education institutions are increasingly expected to play a key role in the collaboration and networking among academia, industry and the public sector to tackle the complex factors fuelling the sustainability crisis.

As highlighted throughout this book, there is an increasing call by scientists and policy makers for interdisciplinary and transdisciplinary research into sustainability issues. In Germany, for instance, transdisciplinary research is considered to be the key to the energy transition process enacted by the Federal Parliament of Germany in summer 2011. This new level of awareness and commitment is a tremendous opportunity, but it also runs the risk of using the reference to transdisciplinary research as a remedy for any kind of complex sustainability-related problem-solving activity (Lang et al., 2012, p. 40), without considering the necessary institutional hurdles to be overcome for the development of the goal-seeking, iterative and integrative approaches needed to address the complex issues of sustainability. As shown both in this book and by leading sustainability scholars, living up to the high expectations of transdisciplinary sustainability research will require structural changes in research organization and funding, in order to build capacity for transdisciplinarity among students and researchers, as well as among stakeholders and decision makers outside academia.

\subsection{AN INSTITUTIONAL REFORM PROGRAMME FOR SUSTAINABILITY SCIENCE}

Achieving the goal of a fully-fledged institutionalization of sustainability science will require efforts and actions to be taken on many levels of policy intervention. This situation can be compared to the emergence of applied research departments at the end of the nineteenth century, in universities 
in the United States and in Europe, on the model of the Massachusetts Institute of Technology (MIT). By organizing applied research at the university, researchers added a new component to the existing missions of the university, then centred around basic research (on the model of the Humboldt University) and teaching (on the model of the first European Universities). The development of transdisciplinary transformative research for sustainability will equally require new components to be added to the research university, based on a gradual process of experimentation and transformation.

The perspective of a process of gradual change is consistent with the conclusion of the overview of promising and/or well-established sustainability science programmes in section 3.4. As highlighted in that section, the various sustainability research programmes integrate the three dimensions of sustainability ethics, interdisciplinarity and transdisciplinarity with varying degrees of strength. For example, some of the research programmes, such as the transition approach to socio-technological change, are more oriented towards problem solving and organized through a transdisciplinary process, while others, such as earth system science, have a stronger interdisciplinary focus. The three dimensions are clearly present in both these programmes, but some of the dimensions are less/more developed in each of them.

Sustainability scholars introduced the distinction between strategic research for sustainable development and sustainability research (Jaeger, 2011, p. 187), which is a convenient way to capture this variability between the transdisciplinary and the interdisciplinary focus. Strategic research for sustainability refers to research support for sustainable development. The main focus of strategic research is on the transdisciplinary collaboration with stakeholders in the elaboration of solutions, such as by mobilizing engineering knowledge that contributes to solving practical problems of sustainability. If such research in addition makes a certain effort to integrate strong sustainability and a systematic interdisciplinary modelling of the coupled socio-ecological system dynamics, then strategic research can be considered as a first-level contribution to sustainability science. The second type, sustainability research, usually refers to the kind of fully developed interdisciplinary research programmes discussed at length in this book. The focus of this second type is mainly on enhancing our understanding of the interactions between economic, socio-technological and ecological systems within a strong sustainability ethics perspective. However, as argued throughout the book, such sustainability research programmes, in so far as their aim is to fully contribute to transformative sustainability science, have to develop, as far as possible, transdisciplinary approaches to organize a practical process for reconciling the plurality of 
ethical values and problem framings that play a role in the social context of the research, even if the latter are not yet fully institutionalized.

The institutional challenges and barriers considered above add an extra layer of variation to these two main types. Indeed, both strategic research for sustainability and sustainability research are often still constructed on an ad hoc and temporary basis. As such, these two modalities for organizing sustainability research do not consider the long-term institutionalization of sustainability research. The latter implies addressing the issues of career rewards, post-graduate training, networking and capacity building for multi-stakeholder partnerships, amongst others. It seems therefore relevant to distinguish between fully-fledged institutionalized research programmes for sustainability and the other two types. The distinction between the three modalities for organizing sustainability research has been represented schematically in Table 5.1.

The most advanced case of institutionalized sustainability research discussed in the book is the graduate programme in sustainability science of the Graduate School of Frontier Sciences at the University of Tokyo

Table 5.1 Gradual change towards fully institutionalized sustainability research

\begin{tabular}{|c|c|c|c|c|}
\hline & 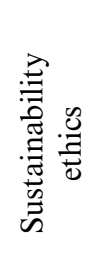 & 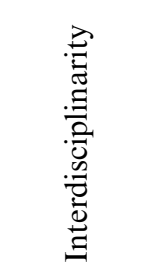 & 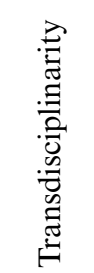 & Example of prototypes \\
\hline $\begin{array}{l}\text { Strategic research } \\
\text { for sustainability }\end{array}$ & + & + & ++ & $\begin{array}{l}\text { Transdisciplinary approaches } \\
\text { to policies for payments for } \\
\text { ecosystem services (Weaver, } \\
\text { 2011). }\end{array}$ \\
\hline $\begin{array}{l}\text { Sustainability } \\
\text { research } \\
\text { programmes }\end{array}$ & $+/++$ & $++/+++$ & + & $\begin{array}{l}\text { Joint Program on Global } \\
\text { Environmental Change and } \\
\text { Food Systems (Ignaciuk et al., } \\
\text { 2012), see section } 3.1 .3\end{array}$ \\
\hline $\begin{array}{l}\text { Fully } \\
\text { institutionalized } \\
\text { sustainability } \\
\text { research }\end{array}$ & +++ & +++ & +++ & $\begin{array}{l}\text { Tokyo University (Yarime et al., } \\
\text { 2012; Onuki and Mino, 2009), } \\
\text { see section 5.2.3 }\end{array}$ \\
\hline
\end{tabular}

Notes: $\quad+=$ early stage $;++=$ well developed $;+++=$ fully integrated. 
(see Chapters 5.2.1, 5.2.2 and 5.2.3). The school offers transdisciplinary education on complex sustainability issues, combining technical courses and case study analysis. In parallel the school has established a research partnership with the local authorities of the district of Kashiwa City for research on urban reforms for low-carbon community development. This research programme includes research clusters on energy, mobility, agriculture and information systems, amongst others. The programme is conducted in combination with a series of social experiments in the local communities. Students of the graduate programme also participate in one of the research clusters and learn transdisciplinary research skills in connection with one of the social experiments. In addition, in 2005, the University of Tokyo launched the journal Sustainability Science in collaboration with the United Nations University, and set up the International Network for Sustainability Science in 2009, which every year organizes the International Conference on Sustainability Science in one of the partner universities.

In Europe, science policy officials have set up major national-level research programmes such as the Knowledge network on System Innovations (KSI) in the Netherlands and the Network for Transdisciplinary Research at the Swiss Academy of Arts and Science (see a detailed description in Box 5.4 below). Another interesting example of an institutionalized sustainability research programme is the Policy Research Centre on Transition for Sustainable Development (Transities voor Duurzame Ontwikkeling, TRADO), funded by the Flemish government. This centre is composed of research units of the KU Leuven, Ghent University, Erasmus University Rotterdam and the strategic research centre Vision on Technology (VITO). The centres assemble researchers from various disciplines, including political science, economics, bio-engineering and architecture. The research programme of TRADO focuses on different aspects of sustainability transitions that have been underdeveloped in the literature and that can support the Flemish Government's transition approach.

As argued throughout section 5.2, sustainability science will not be able to support, in an effective way, the transition to strong sustainability in the absence of such a long-term institutionalization. In particular, academic training is needed to build specific research competences for sustainability research such as ethical argumentation, analysis of socioecological systems and multi-method research. In addition, there is a need for a greater recognition of interdisciplinary and transdisciplinary research within academia, along with confidence building with sustainability stakeholders for transdisciplinary research partnerships. To move in that direction, senior science officials and directors of major higher education 
institutions and research institutions (Scholz et al., 2006; Schneidewind, 2010), have underlined the urgent need to take a minimal set of capacitybuilding measures, to be implemented in the three modalities for organizing sustainability research discussed above:

\subsubsection{Capacity-building Measures at Universities and Other Higher Education Institutions}

First, at the level of strategic science for sustainability, there is an urgent need to transform existing research practices at higher education institutions. This is the most directly available form of bottom-up action that can be envisioned to move towards building a transdisciplinary research infrastructure for sustainability. The minimum conditions highlighted in the literature for such a transformation are the organization of sustainability research in a cross-cutting manner, beyond the borders of disciplines, faculties and colleges, and to give sustainability research a prominent role in the overall strategy of the institutions. Worldwide, many higher education institutions have already taken that road, such as medium-sized universities in some German Länder (Lüneburg University and University of Greifswald (see for a detailed description Box 5.1)) or larger universities in some regions in Japan (Tokyo University in the metropolitan area of Tokyo; see the discussion in the text). Leading figures of these transformations underline the importance of taking the following set of structural reform actions:

- The creation of explicitly designed transdisciplinary professorships (including nomination committees for such positions that are not organized along disciplinary logic). The Lüneburg University in Germany has created such a position in 2009.

- The building of transdisciplinary research centres beyond faculty borders, which can disseminate multi-method research and quality management systems for transdisciplinary research. The transdisciplinary research laboratory at the ETH Zürich is an example of a university that has taken the steps to create such a centre.

- Creation of "bridge" fellowships/professorships for transdisciplinary sustainability research, jointly engaged by higher education institutions and research institutions outside higher education institutions, on the model of research professors at research societies in Germany (Fraunhofer or the Helmholtz societies for instance). 


\section{BOX 5.1 AN EXAMPLE OF CAPACITY BUILDING FOR SUSTAINABLILITY RESEARCH AT HIGHER EDUCATION INSTITUTIONS}

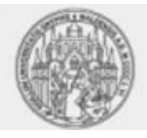

\section{Ernst Moritz Arndt Universität Greifswald Institut für Botanik und Landschaftsökologie}

The Institute of Botany and Landscape Ecology at the University of Greifswald, Germany, has a unique interdisciplinary profile, comprising biologists, ecologists, economists, social and political scientists, and philosophers. The Institute has a long-standing worldwide expertise in the field of landscape and palaeo-ecology, and ecosystem dynamics.

\section{Some Highlights}

- The Working Group Environmental Ethics hosts an interdisciplinary research group on social entrepreneurship (GETIDOS) with specific expertise in empirical social research and collaboration with sustainability stakeholders.

- The Institute hosts an operational foundation (the Michael Succow Foundation) dedicated to the protection of national parks and biosphere reserves in Eastern European countries.

- The institute organizes an international Master's programme in Landscape Ecology and Nature Conservation, with courses in environmental sciences, economics and ethics.

\section{Capacity Building}

- GETIDOS received support from the Social-Ecological Research programme of the Federal Ministry of Education and Research. As stated on the programme's website, social-ecological research aims to develop strategies in order to solve social sustainability issues connecting ecological transformation of the society with social justice and economic demands. This kind of research requires 
cooperation between natural and social scientists and involves social players (for example consumers, local authorities, businesses and NGOs).

- The Michael Succow Foundation at the Institute was established with the prize money from the Right Livelihood Award, established in 1985 with the support of a group of Swedish parliamentarians and with a network of recipients, donors and other supporters covering five continents.

- The International Master's Programme (see above) receives support for tuition fees from the German Academic Exchange Service and from the Deutsche Bundesstiftung Umwelt.

\subsubsection{New Tools for Programmatic Research Funding}

The second starting point for an effective institutionalization of sustainability science is the set of existing programmatic research initiatives on sustainability development and/or environmental issues. Funding for such programmatic research at the regional, national and European level has already equipped some higher education institutions with competences for sustainability research. However, rarely have these been fully exploited for their transdisciplinary research potential. One major research project in Germany, the Klimzug Programme, can illustrate this situation (cited as a failed opportunity by Schneidewind (2010, p. 125), current President of the Wuppertal Institute for Climate, Environment and Energy). This programme for the development of climate adaptation strategies for seven regions in Germany, which received 10 million euros for five years, was a perfect candidate for transdisciplinary research, but in the project design and implementation this aspect remains nearly totally absent. To overcome these failures, it is necessary to go beyond the conventional, purely descriptive-analytical organization of programmatic research and move to the kind of transformative and ethically informed sustainability research that is needed for strong sustainability. Interesting examples of such funded transdisciplinary research programmes are the Local Science Network for Environment and Sustainability, funded by the Japanese Science and Technology Agency (see for a detailed description Box 5.2), the TRANSMED project of the French National Research Agency for the transdisciplinary study of the future of the Mediterranean area (http://www.agence-nationale-recherche.fr) and the Policy Research Centre on Transitions for Sustainable Development funded by the Flemish Government in Belgium. The following capacity-building 


\section{BOX 5.2 AN EXAMPLE OF CAPACITY BUILDING FOR SUSTAINABILITY RESEARCH THROUGH TOOLS WITHIN PROGRAMMATIC RESEARCH FUNDING}

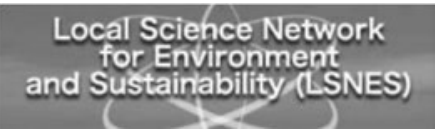

The Local Science Network for Environment and Sustainability is part of the project on Constructing a Pragmatic Science Community, funded by the Japan Science and Technology Agency (http://localsci.org/jst2en/outline.html). This project aims to build a system to facilitate interactions between stakeholders, residential research institutions and visiting researchers in local efforts to address environmental issues. The project also addresses evaluation and feedback from local community stakeholders in such a system.

\section{Some Highlights}

- The Local Science Network fosters and supports scientists who can be useful partners to the local stakeholders that are responsible for solving problems.

- The Local Science Network organizes a Participatory Research Evaluation system for use in evaluating the activities and research of scientists from the perspectives of both local communities and science itself.

\section{Capacity Building}

- LSNES organizes residential research internships, which involve training on how residential researchers work on problems and how they approach and apply research in the field.

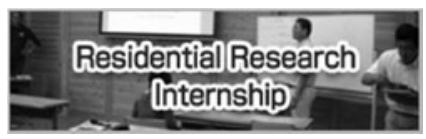


- LSNES formulates Guidelines on Collaborations, which the local stakeholders and scientists/specialists then use to motivate and evaluate each other and to work together in scientific collaborations.

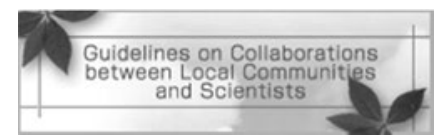

measures can be taken to integrate ethically informed transdisciplinary research in programmatic research funding:

- integration of requirements for transdisciplinary organization of research and explicit justification of the choices regarding options for a strong sustainability ethics as a condition for access to programmatic research funding for sustainability research;

- support for systematic exchange on methodologies and best practices for sustainability research between existing institutions involved in sustainability research;

- synergy grants for a consortium of institutions, with the view to building cross-institutional methodological competences on sustainability research;

- cross-institutional competence centres for sustainability research, which can integrate knowledge on sustainability research methodologies from higher education and other research institutions.

\subsubsection{New Research Networks and Institutions}

Third, the full institutionalization of sustainability research will require the creation of new research networks and/or institutions specifically dedicated to sustainability research. On the one hand, new research networks should be created to address one of the following tasks:

- strengthening the capacity to participate in international networks, by gathering and disseminating best practices and know-how;

- supporting the creation of common transdisciplinary research infrastructures such as peer-reviewed open access journals, prices for sustainability research and annual conferences on transdisciplinary sustainability research; 
- promoting the joint submission of funded research projects at the regional, national and European level, amongst higher education institutions and research institutions outside higher education institutions.

Prominent examples of such networks are the Alliance for Global Sustainability on the international level (see detailed description in Box 5.3) and the Sustainability Transitions Research Network (STRN) in Europe.

On the other hand, fully-fledged new institutions for transdisciplinary research, on the regional, national or transnational scale, should be created in order to accomplish a long-term institutionalization of sustainability research. The following institutions can contribute to that goal:

- Regional or national panels, on the model of the Intergovernmental Panel on Climate Change (IPCC), which make peer-reviewed inventories of the best available scientific knowledge on strategies and solutions for transition to strong sustainability at the regional or national level.

- A fund for transformative sustainability research that would specifically finance research topics emanating from sustainability stakeholders (in a competitive submission process of topics identified by these social actors and practitioners). The aim of such a fund (or part of an existing fund) would be to involve sustainability stakeholders in the definition of the salient and socially relevant research questions to be addressed in sustainability research.

- An institute for advanced studies in sustainability research (which can be organized in one location or in a network of partner institutions), which provides an infrastructure for hosting high-level visiting scholars and coordinates work with graduate students and post-docs on innovative and path-breaking ideas for taking the sustainability research agenda forward.

- An advisory body for the development of sustainability research at higher education institutions. Such a body can provide reports on international best practices and develop criteria for quality management of transdisciplinary sustainability research.

Examples of such new institutions that have an important capacitybuilding role are the Institute for Advanced Sustainability Studies in Potsdam (IASS), the Td-net at the Swiss Academies of Arts and Science (see a detailed description in Box 5.4) and the Centre for International Climate and Environmental Research in Oslo (see Table 5.2).

Many regions and communities at present still do not have major 


\section{BOX 5.3 AN EXAMPLE OF CAPACITY BUILDING FOR SUSTAINABILITY RESEARCH THROUGH SUPPPORT FOR RESEARCH NETWORKS}

\section{'AGS}

The Alliance for Global Sustainability (AGS) (http://www. globalsustainability.org/) is a unique, international partnership between four science and technology universities:

- Swiss Federal Institute of Technology, Zurich (ETH Sustainability)

- Massachusetts Institute of Technology (MIT/AGS)

- University of Tokyo (UT)

- Chalmers University of Technology (Chalmers)

Since its inception, the AGS has pioneered a new research paradigm that brings together multi-disciplinary research teams from the partner institutions. Strong, local programmes engage faculty, students and senior research staff from across their respective institutes.

\section{Capacity Building}

- Flagship programmes: building upon 10 years of collaborative research, the AGS has launched two flagship programmes of integrated research, education and outreach: (1) the Energy Flagship, which focuses on select energy sectors under the theme Near-Term Pathways to a Sustainable Energy Future; (2) the flagship on food and water: Secure Ecosystem Services for a Nourished World.

- Joint educational activities undertaken by AGS member institutions include the "Youth Encounter on Sustainability" and the "Delivering Research Results" projects. The latter aims at creating a web-based educational resource to engage the interest of undergraduates in sustainability 
research, develop course materials and support their coursework and research.

- The AGS book series, "Science and Technology: Tools for Sustainable Development" (Springer) has published nine volumes, with more in the pipeline.

- The Partnership Simulation tool, developed by MIT Professor Lawrence Susskind and his team especially for the AGS. The exercise is aimed at building capacity for starting and implementing an effective research partnership for sustainable development across academia/ industry/civil society.

\section{BOX 5.4 AN EXAMPLE OF CAPACITY BUILDING FOR SUSTAINABILITY RESEARCH THROUGH BUILDING OF NEW INSTITUTIONS}

\section{td-net}

Network for Transdisciplinary Research

Since 2008 the Network for Transdisciplinary Research (tdnet) has been an initiative of the Swiss Academies of Arts and Sciences. The network was initiated to advance transdisciplinary research in all thematic fields. Its origins are, however, within the experiences made in the fields of environmental and sustainability research.

\section{Some Highlights}

- td-net is the primary Swiss contact point for researchers and funders in the field of inter- and transdisciplinary research and teaching.

- As a platform, td-net advances the mutual learning between inter- and transdisciplinary researchers and lecturers across thematic fields, languages and countries and thereby supports community building. 
- As centre of competences, td-net makes use of expertise, methods and tools for coproducing knowledge. By use of these competences td-net supports inter- and transdisciplinary projects in research and teaching in order to bring them to fruition.

- td-net assists the Swiss Academies of Arts and Sciences in facilitating exchange and collaboration between disciplines and between science and society.

\section{Capacity Building}

- The national inter- and transdisciplinarity conference is jointly organized by td-net and the Institut Universitaire Kurt Bösch (IUKB). The conference aims to foster exchange of ideas about the challenges of inter- and transdisciplinary teaching and research.

- The Swiss Academies Award for Transdisciplinary Research (td-award) is given every other year in recognition of outstanding transdisciplinary work.

- Td-net will in the period 2012-15 elaborate an overview of methods for co-producing knowledge, which assigns the methods to the specific problem they are suited to address; develops selected methods by practically testing and exploring them; and publishes the application-driven overview of methods on their home page.

institutionalized sustainability research infrastructures, with the notable exception of the cases discussed above. In spite of this, the sustainability challenges in the field of energy, mobility or agriculture - to name just a few - are as important everywhere. Therefore, the development of specific strategies, networks and institutions for sustainability research is likewise needed for addressing these challenges. The opportunities to move in that direction are certainly available. Indeed, universities and research centres already develop various initiatives and research programmes that can directly contribute to the building of such an infrastructure. However, without new ambitious initiatives at various levels of policy intervention, these current initiatives will fall short of upgrading their infrastructures to the level of international excellence already reached in the prominent examples discussed in this chapter. 
Table 5.2 Capacity-building measures for transdisciplinary sustainability science

\begin{tabular}{l} 
Capacity-building measures for transdisciplinary \\
sustainability science \\
\hline Capacity-building measures at higher education \\
institutions \\
Establishment of transdisciplinary professorships \\
Building of transdisciplinary research centres \\
Creation of "bridging" fellowships
\end{tabular}

Tools within programmatic research funding Requirements of transdisciplinary organization of research

Requirements of strong sustainability ethics perspective

Synergy grants for cross-institutional multi-method sustainability research

Cross-institutional competence centres

Research networks

Sharing best practices and know-how for international networking

Common transdisciplinary research infrastructure (journals, conferences, prices)

Joint submission of larger research projects

Research institutions/platforms/panels

Regional or national sustainability panels

Organization of stakeholder identification/submission of salient research questions

Institute for advanced studies in sustainability research

Advisory body on quality management procedures for transdisciplinary sustainability research
Illustrative examples cited in the book $(*)$

Institute of Botany and Landscape Ecology (see Box 5.1); Lüneburg University, ETH Zürich and Graduate School of Frontier Sciences at Tokyo University (see text)

Local Science Network for Environment and Sustainability (see Box 5.2); TRANSMED project and Policy Research Centre on Transition for Sustainable Development (see text)

Alliance for Global

Sustainability (see Box 5.3); Sustainability Transitions Research Network STRN (see text)

Td-net at the Swiss Academies of Arts and Sciences (see Box 5.4); IASS Potsdam and Centre for International Climate and Environmental Research (Oslo) (see text)

Notes: These measures can be the object of new science policy initiatives or can be integrated into existing science policy initiatives. $\left(^{*}\right)$ The list of examples in the second column is only given for illustrative purposes. A full presentation of existing initiatives is beyond the scope of the analysis in this book. Therefore, this list is not representative of all initiatives existing in these or other countries. 